\title{
EFEKTIVITAS PENDIDIKAN KESEHATAN METODE PEER GROUP EDUCATION DENGAN METODE DEMONSTRASI TERHADAP KETERAMPILAN SADARI
}

\author{
Weni Tri Purnani ${ }^{1}$, Binti Qoni'ah ${ }^{2}$ \\ ${ }^{1}$ Program Studi D-IV Bidan Pendidik, Fakultas Ilmu Kesehatan, Universitas Kadiri \\ ${ }^{2}$ Program Studi D-IV Bidan Pendidik, Fakultas Ilmu Kesehatan, Universitas Kadiri \\ tripurnani03330@gmail.com
}

\begin{abstract}
According WHO ranks, breast cancer be second ranks after cervical cancer. Breast self examination is an important first step to know early about tumor or lump in breast. The purpose of this research to determine the difference and effectiveness of health education by peer group methode and used demonstration methode of breast self examnination skills at SMAN 1 Kediri teenager in SMAN 1 Kediri. The design of this study was True Experimental with post test only control design. The samples were 16 respondent for control group and 16 treatment group respondents in SMAN 1 Kedir. The technique of this sampling was simple random sampling. The Data collection USED observasi sheets. The data were analyzed for Hipotesist using Maan Whitney test. The result of this research showed that 16 girls in the peer group education method, almost all of them, 13 respondent (81,3\%) know how to checkup their own breast, while the group in the demonstration method was half respondent, 7 respondent (43,8\%) were less skill checkup for own breast. Based on the Mann Whitney Statistic test pvalue $=0,000$ which smaller than the significance level $(\alpha=0.05)$, so it can be said $p<\alpha$ the $\mathrm{HO}$ is rejected and $\mathrm{HI}$ is accepted. It meant this research found out that the difference of effectiveness health education by peer group education than demonstration method on Breast self examination skills in SMAN 1 Kediri teenager. From the findings, the researcher does hope that the peer group method may be one alternative used in teaching and learning especially for psychomotor learning.
\end{abstract}

Keywords: Health Education, Peer Group, Breast Self Examination

\begin{abstract}
ABSTRAK
Kanker payudara menurut WHO menduduki peringkat kedua setelah kanker leher rahim. SADARI merupakan langkah awal yang penting untuk mengetahui secara dini adanya tumor atau benjolan pada payudara. Menganalisis perbedaan efektivitas pendidikan kesehatan metode peer group education dengan metode demonstrasi terhadap keterampilan pemeriksaan payudara sendiri (SADARI) pada remaja putri di SMAN 1 Kota Kediri merupakan tujuan dari penelitian ini. Desain Penelitian ini yaitu kuasi eksperimental dengan menggunakan rancangan posttest only control design. Seluruh remaja putri di SMAN 1 Kota Kediri yang menjadi populasi dalam penelitian ini. Sampel penelitian ini adalah sebagian remaja putri di SMAN 1 Kota Kediri sebesar 16 responden untuk kelompok kontrol dan 16 responden kelompok perlakuan. Teknik simple random sampling adalah teknik pengambilan sample yang digunakan. Lembar observasi digunakan untuk proses pengumpulan data. Menggunakan Uji Mann whitney untuk menganalisis. Hasil penelitian menunjukkan bahwa dari 16 orang remaja putri di SMAN 1 Kota Kediri pada kelompok metode peer group education hampir seluruhnya yaitu 13 responden $(81.3 \%)$ terampil melakukan pemeriksaan payudara sendiri sedangkan kelompok pada kelompok metode demonstrasi, hampir setengah dari responden yaitu 7 responden (43.8\%) kurang terampil dalam melakukan pemeriksaan payudara sendiriBerdasarkan hasil uji statistik Mann whitney diperoleh nilai $\mathrm{p}$ Value $=0,000$ yang lebih kecil dari taraf nyata $(\alpha=0,05)$ sehingga dapat dikatakan $\mathrm{p}<\alpha$ maka $\mathrm{H} 0$ ditolak dan $\mathrm{H} 1$ diterima artinya terdapat perbedaan efektivitas pendidikan kesehatan metode Peer Group Education dengan metode demonstrasi terhadap keterampilan pemeriksaan payudara sendiri (SADARI) pada remaja putri di SMAN 1 Kota Kediri. Disarankan untuk mengaplikasikan metode peer group education sebagai salah satu metode pembelajaran khususnya untuk pembelajaran psikomotor.
\end{abstract}

Kata Kunci: Pendidikan Kesehatan, Pendidikan Sebaya, SADARI 
Weni, et.al. Efektivitas Pendidikan Kesehatan Metode Peer Group Education Dengan Demostrasi Terhadap Keterampilan Sadari

\section{PENDAHULUAN}

Menurut WHO (Word Health Organization), kanker payudara menempati peringkat kedua di Indonesia setelah kanker leher rahim. Prevalensi tumor/kanker di Indonesia adalah 1,4 per 1000 penduduk, atau sekitar 330.000 orang. Insidens kanker payudara pada perempuan di Indonesia sebesar 40 per 100.000 perempuan (Badan Penelitian dan Pengembangan Kesehatan, 2013). Menurut Laporan Tahunan Rumah Sakit pada 2012 didapati bahwa carcinom Mammae merupakan salah satu kasus penyakit terbanyak pasien rawat inap di rumah sakit umum pemerintah. Penyakit tersebut mencapai hingga 7.487 kasus setelah anemia dan hipertensi. Wanita yang sudah berusia diatas 30 tahun lebih mudah untuk terserang kanker. Disamping itu, saat ini sudah muncul kanker payudara pada wanita usia remaja. Hal ini didukung berdasarkan laporan Badan Kesehatan Dunia WHO (World Health Organization), pada tahun 2011 jumlah wanita khususnya remaja penderita kanker payudara mencapai 1.150 .000 orang, 700.000 diantaranya tinggal di negara berkembang, termasuk Indonesia (Badan Penelitian dan Pengembangan Kesehatan, 2013).

Provinsi Jawa Timur tahun 2013 estimasi jumlah penderita kanker payudara pada sebesar 0,5\% sekitar 9.688 orang (Badan Penelitian dan Pengembangan Kesehatan, 2013). pada tahun 2014 berdasarkan data Dinas Kesehatan Jawa Timur ada 3.112 jiwa dan terjadi kasus kematian 165 orang. Pada bulan Januari sampai September 2015, di Kota Kediri di dapatkan 39 orang menderita kanker payudara (Dinkes Kota Kediri, 2015). Berdasarkan data tersebut dapat disimpulkan bahwa masih ada kejadian kanker payudara di Kota Kediri.

Secara teori penyebab pasti dari kanker payudara belum diketahui secara pasti, tetapi ada beberapa faktor resiko terjadinya kanker payudra antara lain faktor internal dan eksternal. Faktor internal yaitu riwayat keluarga, pengaruh hormon estrogen berlebihan, menstruasi terlalu dini, tidak menikah, tidak menyusui, dan menoupose terlambat. Faktor eksternal sendiri antara lain pola makan tidak baik, merokok, minum-minum alkohol, dan polusi (Romauli, 2011).

Secara praktis disebabkan karena terbatasnya pengetahuan masyarakat tentang bahaya kanker, tanda-tanda dini dari kanker, faktor-faktor resiko terkena kanker, cara penanggulangannya secara benar serta
JPH RECODE Oktober 2018; 2 (1) : 69-75 http://e-journal.unair.ac.id/JPHRECODE

membiasakan diri dengan pola hidup sehat. Tidak sedikit dari mereka yang terkena kanker, datang berobat ketempat yang salah dan baru memeriksakan diri ke sarana pelayanan kesehatan ketika stadiumnya sudah lanjut sehingga biaya pengobatan lebih mahal (Yayasan Kanker Indonesia, 2012).

Melihat tingginya angka penderita kanker atau tumor payudara, dan beberapa faktor penyebab yang bisa memicu kanker payudara, untuk itu perlu tindakan deteksi dini tumor/kanker payudara melalui pemeriksaan payudara sendiri (SADARI). Kegiatan pemeriksaan SADARI ini paling efektif dilaksanakan pada usia remaja karena pada usia tersebut merupakan saat yang tepat untuk memulai tindakan preventif deteksi dini terjadinya penyakit Fibroadenoma Mammae (FAM) dan Cancer Mammae. Hasil penelitian para ahli yang dikutip oleh (Dalimartha, 2006) menjelaskan bahwa keganasan payudara ditemukan dengan pemeriksaan payudara sendiri (SADARI) sekitar 75-82\%.

Berdasarkan hasil survey pendahuluan yang peniliti laksanakan di SMAN 1 Kota Kediri. Pada studi pendahuluan tersebut, peneliti juga mewawancarai 10 siswi, isi wawancara mengenai hal-hal yang berkaitan dengan pemeriksaan payudara sendiri (SADARI). Dari hasil wawancara ditemukan $80 \%$ (8 siswi) tidak pernah tau tentang (SADARI), 10\% (1 siswi) sudah tahu tentang SADARI, dan 10\% (1 siswi) baru ingin tau tentang SADARI. Serta keseluruhan siswi belum pernah melakukan praktik SADARI. Mengingat masih rendahnya keterampilan SADARI pada siswi maka sangatlah penting untuk dilakukan pendidikan kesehatan kesehatan reproduksi terutama tentang SADARI.

Di SMAN 1 Kota Kediri sendiri saat ini belum pernah ada yang memberikan penyuluhan ataupun pelatihan Pemeriksaan Payudara Sendiri (SADARI) yang diberikan kepada para siswi langsung ataupun melalui pendidikan teman sebaya sehingga banyak remaja yang belum mengetahui tentang SADARI. Padahal SADARI merupakan salah satu tindakan deteksi dini kanker payudara. Remaja putri perlu memahami hal ini agar dapat melakukan deteksi dini kanker payudara sejak dini.

Remaja memerlukan sebuah pelayanan kesehatan, salah satu diantaranya pendidikan kesehatan yang baik dan benar. Pendidikan 
kesehatan akan lebih baik bila diberikan langsung di sekolah melalui teman sebaya mereka. Teman sebaya dapat akan lebih efektif dan terbuka dalam memberikan pendidikan kesehatan sehingga komunikasi akan terjalin lebih mudah di bandingkan dengan pendidikan yang dilakukan oleh orang tua dan guru. Pendidikan kesehatan sebaya adalah salah satu bentuk promosi kesehatan dalam rangka mengurangi risiko buruk kesehatan. Metode yang digunakan adalah dengan komunikasi dan diskusi oleh teman yang seusia atau disebut peer group educator yang telah melewati proses pelatihan serta pemberian informasi. Teman Sebaya yang menjadi peer group educator berperan penting dalam melakukan pendidikan kesehatan. Merak tidak hanya memberikan informasi yang sudah didapatkan saat pelatihan, naun juga turut menjadi contoh nyata bagi teman yang lain.(Amelia, 2014).

Melalui Peer group education maka dihapkan kegiatan SADARI (pemeriksaan payudara sendiri) dapat ditingkatkan sehingga untuk mendeteksi kanker payudara sejak dini.
Tujuan penelitian ini adalah untuk mengetahui perbedaan efektivitas pendidikan kesehatan metode peer group education dengan metode demonstrasi terhadap Keterampilan Pemeriksaan Payudara Sendiri (SADARI) pada remaja putri di SMAN 1 Kota Kediri.

\section{METODE}

Rancangan bangun penelitian yang digunakan dalam penelitian ini Kuasi Eksperimental dengan menggunakan desain Posttest Only Control Design. Populasi penelitian ini adalah seluruh remaja putri di SMAN 1 Kota Kediri. Sampel penelitian ini sebagian remaja putri di SMAN 1 Kota Kediri sebesar 16 responden untuk kelompok kontrol dan 16 responden kelompok perlakuan. Teknik sampling yang digunakan adalah teknik Simple Random Sampling. Pengumpulan data menggunakan lembar observasi. Analisa untuk menguji hipotesis menggunakan uji Mann whitney.

\section{HASIL}

Tabel 1. Distribusi Frekuensi Responden Berdasarkan Usia pada Kelompok Metode Peer Group Education di SMAN 1 Kota Kediri

\begin{tabular}{|c|c|c|}
\hline Usia (Tahun) & Frekuensi (n) & Presentase (\%) \\
\hline 16 & 5 & 31.25 \\
17 & 11 & 68.75 \\
\hline Total & 16 & 100 \\
\hline
\end{tabular}

Sumber : data primer 2018

Berdasarkan tabel diatas didapatkan hasil bahwa sebagian besar 11 responden $(68.75$ $\%)$ berusia 17 tahun.

Tabel 2. Distribusi Frekuensi Responden berdasarkan Usia pada Kelompok Metode Demonstrasi di SMAN 1 Kota Kediri

\begin{tabular}{|c|c|c|}
\hline Usia (Tahun) & Frekuensi (n) & Presentase $(\%)$ \\
\hline 16 & 5 & 31.25 \\
17 & 9 & 56.25 \\
18 & 2 & 12.5 \\
\hline Total & 16 & 100 \\
\hline
\end{tabular}

Sumber : data primer 2018

Berdasarkan tabel diatas didapatkan hasil bahwa sebagian besar 9 Responden (56.25 $\%$ ) berusia 17 tahun. 
Terhadap Keterampilan Sadari

Tabel 3. Distribusi Frekuensi Responden Berdasarkan Sumber Informasi Pendidikan Tentang Kanker Payudara pada Kelompok Metode Peer Group Education di SMAN 1 Kota Kediri

\begin{tabular}{|l|c|c|}
\hline \multicolumn{1}{|c|}{ Sumber Informasi } & Frekuensi (n) & Presentase (\%) \\
\hline Tidak Pernah & 12 & 75 \\
Masyarakat & 1 & 6.25 \\
Media & 3 & 18.75 \\
\hline \multicolumn{1}{|c|}{ Total } & 16 & 100 \\
\hline
\end{tabular}

Sumber : data primer 2018

Berdasarkan tabel diatas didapatkan hasil kanker payudara. bahwa hampir seluruhnya, yaitu 12 responden $(75 \%)$ tidak pernah mendapat informasi tentang

Tabel 4. Distribusi Frekuensi Responden Berdasarkan Sumber Informasi Pendidikan Tentang Kanker Payudara pada Kelompok Metode Demonstrasi di SMAN 1 Kota Kediri

\begin{tabular}{|c|c|c|}
\hline Sumber Informasi & Frekuensi (n) & Presentase (\%) \\
\hline Tidak Pernah & 11 & 68.75 \\
\hline Masyarakat & 1 & 6.25 \\
\hline Keluarga & 1 & 6.25 \\
\hline Media & 3 & 18.75 \\
\hline Total & 16 & 100 \\
\hline
\end{tabular}

Sumber : data primer 2018

Berdasarkan tabel diatas didapatkan hasil bahwa hampir seluruhnya, yaitu 11 responden

tentang kanker payudara.

$(68.75 \%)$ tidak pernah mendapat informasi

Tabel 5. Keterampilan Pemeriksaan Payudara Sendiri (SADARI) dengan Metode Peer Group Education Sesudah Diberikan Pendidikan Kesehatan Pada Remaja Putri di SMAN 1 Kota Kediri

\begin{tabular}{|c|c|c|}
\hline Keterampilan SADARI & $\mathrm{n}$ & $(\%)$ \\
\hline Kurang Terampil & 3 & 18.8 \\
\hline Terampil & 13 & 81.3 \\
\hline Total & 16 & 100 \\
\hline
\end{tabular}

Sumber: data primer, 2018

Berdasarkan tabel diatas didapatkan hasil bahwa hampir seluruhnya yaitu 13 responden $(81.3 \%)$ terampil melakukan pemeriksaan payudara sendiri.

Tabel 6. Distribusi frekuensi Keterampilan pemeriksaan payudara sendiri (SADARI) dengan Metode Demonstrasi sesudah diberikan pendidikan kesehatan pada remaja putri di SMAN 1 Kota Kediri

\begin{tabular}{|c|c|c|}
\hline Keterampilan SADARI & $\mathrm{n}$ & $(\%)$ \\
\hline Tidak terampil & 6 & 37.5 \\
\hline Kurang terampil & 7 & 43.8 \\
\hline Terampil & 3 & 18.8 \\
\hline Total & 16 & 100 \\
\hline
\end{tabular}

Sumber: data primer, 2018 
Berdasarkan tabel diatas didapatkan hasil bahwa yang diberikan pendidikan kesehatan dengan metode demonstrasi, hampir setengah dari responden yaitu 7 responden $(43.8 \%)$ kurang terampil dalam melakukan pemeriksaan payudara sendiri.

Tabel 7. Tabulasi silang Perbedaan Efektivitas Pendidikan Kesehatan Metode Peer Group Education dengan Metode Demonstrasi terhadap keterampilan pemeriksaan payudara sendiri (SADARI) pada remaja putri di SMAN 1 Kota Kediri

\begin{tabular}{|c|c|c|c|c|c|c|c|c|c|}
\hline \multirow{3}{*}{ Metode } & \multicolumn{5}{|c|}{ Keterampilan SADARI } & \multirow{2}{*}{\multicolumn{2}{|c|}{ Terampil }} & \multicolumn{2}{|r|}{ Total } \\
\hline & & Tidak & & & & & & & \\
\hline & $n$ & $\%$ & $\mathrm{n}$ & & $\%$ & $\mathrm{n}$ & $\%$ & $\mathrm{n}$ & $\%$ \\
\hline Peer & 0 & 0 & 3 & 9.375 & & 13 & 40. & 16 & 50 \\
\hline $\begin{array}{c}\text { Group } \\
\text { Education }\end{array}$ & & & & & & & & & \\
\hline Demons- & 6 & 18.75 & 7 & 21.87 & & 3 & 9.3 & 16 & 50 \\
\hline Total & 6 & 18.7510 & & 31.2 & 5 & 16 & 50 & 32 & 100 \\
\hline$\rho=0.000$ & & $\alpha=0.05$ & & & & & & & \\
\hline
\end{tabular}

Sumber: data primer 2018

Berdasarkan tabel diatas didapatkan hasil bahwa uji perbedaan pendidikan kesehatan metode Peer Group Education dengan metode demonstrasi terhadap keterampilan pemeriksaan payudara sendiri (SADARI) pada remaja putri di SMAN 1 Kota Kediri mempunyai nilai signifikansi (p) sebesar 0.000 yang lebih kecil dari alpha 0.05 ,

\section{PEMBAHASAN}

Diketahui bahwa dari 16 orang remaja putri di SMAN 1 Kota Kediri yang diberikan pendidikan kesehatan dengan metode peer group education, hampir seluruhnya yaitu 13 responden (81.3\%) terampil melakukan pemeriksaan payudara sendiri. Keterampilan melakukan SADARI yang tergolong terampil pada remaja putri di SMAN 1 Kota Kediri disebabkan karena mendapat pendidikan kesehatan dengan metode peer group education, yaitu metode pembelajaran yang dilakukan dengan cara memberdayakan siswa yang memiliki daya serap yang tinggi dari kelompok siswa itu sendiri untuk menjadi tutor bagi teman-temannya, dimana siswa yang menjadi tutor bertugas untuk memberikan materi belajar dan latihan kepada teman-temannya (tutee) sehingga Ho ditolak dan dapat disimpulkan bahwa terdapat perbedaan efektivitas pendidikan kesehatan metode Peer Group Education dengan metode demonstrasi yang signifikan (bermakna) terhadap keterampilan pemeriksaan payudara sendiri (SADARI) pada remaja putri di SMAN 1 Kota Kediri. yang belum faham terhadap materi/ latihan yang diberikan guru dengan dilandasi aturan yang telah disepakati bersama dalam kelompok tersebut, sehingga akan terbangun suasana belajar kelompok yang bersifat kooperatif bukan kompetitif (Ahmad, 2013)

Hasil yang didapatkan pada Kelompok perlakuan dalam melakukan keterampilan SADARI dengan hasil maksimal yaitu dalam kategori terampil, hal ini sesuai dengan teori bahwa dengan metode peer group education dapat meningkatkan motivasi, juga dapat meningkatkan pendalaman pengetahuan serta keterampilan dengan dibimbing oleh tutor sebaya (teman sendiri). Selain itu peran tutor sebaya membantu meningkatkan rasa tanggung jawab seseorang untuk belajar dan menjadi terampil sehingga mereka terpacu untuk belajar dan mempraktekkan SADARI secara bersama.

Diketahui bahwa dari 16 orang remaja putri di SMAN 1 Kota Kediri yang diberikan 
pendidikan kesehatan dengan metode demonstrasi, hampir setengah dari responden yaitu 7 responden (43.8\%) kurang terampil dalam melakukan pemeriksaan payudara sendiri.

Muhibbin (2000) metode demonstrasi adalah metode mengajar dengan cara memperagakan barang, kejadian, aturan dan urutan melakukan sesuatu kegiatan, baik secara langsung maupun melalui penggunaan media pembelajaran yang relevan dengan pokok bahasan atau materi yang sedang disajikan beberapa keunggulan atau kelebihan metode demonstrasi menurut Roestiyah (1991) yaitu perhatian siswa lebih dipusatkan pada materi yang sedang diberikan, konsep yang diterima siswa lebih mendalam sehingga lebih lama dalam jiwanya, memberikan motivasi yang kuat pada siswa agar lebih giat belajar karena siswa dilibatkan dengan pelajaran.

Berdasarkan teori diatas peneliti menyimpulkan bahwa metode demonstrasi merupakan teknik guru dalam mengajar dengan memeragakan dan mempertunjukkan kepada siswa suatu proses, situasi, kejadian, urutan melakukan suatu kegiatan atau benda tertentu yang sedang dipelajari baik dalam bentuk yang sebenarnya maupun tiruan melalui penggunaan berbagai macam media yang relevan dalam penelitian ini adalah memeragakan tentang SADARI untuk memudahkan siswa memahami materi. Akan tetapi hasil penelitian menunjukkan hal sebaliknya yang terjadi di kelompok metode demonstrasi yaitu kurang terampilnya dari kelompok metode demonstrasi, menurut peneliti hal tersebut dapat disebabkan karena tidak adanya tindakan lebih lanjut dari peneliti misalnya siswi remaja putri diminta untuk memeragakan kembali satu persatu ap yang sudah di demonstrasikan dengan didampingi peneliti tetapi dalam proses penelitian ini responden hanya diberikan standar operasional prosedur dari SADARI dan selanjutnya responden diminta untuk belajar secara mandiri, hal tersebut sesuai dengan teori menurut Muhibbin (2000), yang menyebutkan bahwa metode demonstrasi menjadi tidak efektif jika siswa tidak turut aktif dan gaduh.

Hasil uji perbedaan pendidikan kesehatan metode Peer Group Education dengan metode demonstrasi terhadap keterampilan pemeriksaan payudara sendiri (SADARI) pada remaja putri di SMAN 1 Kota Kediri mempunyai nilai signifikansi (p) sebesar 0.000 yang lebih kecil dari alpha 0.05 , sehingga Ho ditolak dan dapat disimpulkan bahwa terdapat perbedaan pendidikan kesehatan metode Peer Group Education dengan metode demonstrasi yang signifikan (bermakna) terhadap keterampilan pemeriksaan payudara sendiri (SADARI) pada remaja putri di SMAN 1 Kota Kediri.

Pentingnya deteksi dini tumor atau kanker payudara dalam hal ini adalah untuk mendeteksi kanker payudara sejak dini dan upaya ini perlu dipahami dan dilakukan oleh remaja putri. Sesuai dengan pengertian SADARI itu sendiri yaitu usaha atau cara pemeriksaan payudara yang secara teratur dan sistemik dilakukan oleh wanita itu sendiri yang merupakan bagian tidak terpisahkan dari program screening atau deteksi dini (Romauli, 2011).

Penanganan yang dilakukan untuk meningktakan keterampilan remaja putri untuk melakukan SADARI adalah melakukan pendidikan kesehatan dari hasil penelitian didapatkan bahwa metode peer group education adalah metode yang efektif jika dibandingkan dengan metode demonstrasi. Pada kelompok metode peer group education peneliti memberikan pendidikan kesehatan dengan metode demonstrasi terlebih dahulu kepada kelompok dan kemudian peneliti memilih satu orang sebagai tutor yang bertugas untuk memberikan materi belajar dalam hal ini adalah mendemonstrasikan ulang keterampilan SADARI dan melatih kepada teman-temannya yang belum memahami terhadap materi/ latihan yang diberikan oleh peneliti. Imron (2012) menyatakan bahwa saat remaja mendiskusikan permasalah yang berkaitan kesehatan reproduksi maka mereka akan mersa lebih leluasa untuk terbuka dan merasa nyaman ketika dengan teman sebayannya. Maka hal-hal yang selama ini dianggap tabu saat dibicarakan oleh orangtua dan guru khususnya menganai SADARI akan diberikan oleh teman sebayanya sehingga tidak lagi lau untuk membicarakannya. Informasi yang tersampaikan mengenai SADARI akan memberntuk siklus dari remaja, disampaikan oleh remaja, dan untuk remaja.

Salah satu faktor yang mempengaruhi 
pengetahuan tentang SADARI adalah umur. Hal tersebut juga sudah dibuktikan keefektivitasannya melalui metode peer group education. Diketahui bahwa dari 16 responden didapatkan hasil sebagian besar 11 responden $(68.75 \%)$ berusia 17 tahun. Cahyaningsih (2017) dalam penelitiannya mengungkapkan bahwa remaka umur 17-20 tahun adalah masa dimana telah mencapai stadium berpikir secara operasional. Mereka memiliki kemampuan untuk memproses pesan. Responden berumur 17 tahun didominasi masuk dalam kategori terampil di waktu penrkembangan menuju kedewasaan dan perlu mengembangkan sistem penilaian individual. Sistem penilaian tersebut adalah pengambilan keputusan tentang sesorang memberikan respon terhadap suatu stimulus yang meragukan.

Faktor lain adalah pendidikan. Pendidikan adalah suatu cara untuk mendapatkan informasi semisal tentang kesehatan yang dapat meningkatkan kualitas hidup. Pendidikan juga mempengaruh perilaku akan pola hidup terutama pada motivasi diri (Wawan dan Dewi, 2012). Umumnya, semakin tinggi pendidikan seseorang maka akan semakin mudah untuk menerima seuah informasi. Responden penelitian ini adalah kelas XI , masa ini merupakan masa remaja tingkat SMA dimana dalam proses berpikir bisa lebih matang sehingga informasi SADARI akan lebih mudah dipahami.

\section{KESIMPULAN}

Terdapat Perbedaan Efektivitas Pendidikan Kesehatan Metode Peer Group Education dengan Metode Demonstrasi terhadap keterampilan pemeriksaan payudara sendiri (SADARI) pada remaja putri di SMAN 1 Kota Kediri.

\section{SARAN}

Peneliti menyarankan untuk mengaplikasikan metode peer group education sebagai salah satu metode pembelajaran khususnya untuk pembelajaran psikomotor, kasus-kasus yang sulit untuk dipecah.

\section{DAFTAR PUSTAKA}

Ahmad, S. 2013. Teori Belajar Dan Pembelajaran di Sekolah Dasar. Jakarta: Kencana Prenada Media Group.

Amelia, C. R. 2014. Pendidikan Sebaya Meningkatkan Pengetahuan Sindrom Pramenstruasi pada Remaja Peer Education Improve Premenstrual Syndrome Knowledge in Adolescent. Jurnal Kedokteran Brawijaya, 28(2), pp. 152-154. Diakses dari: file:///C:/Users/HALIMAH PC/Downloads/413-1933-2-PB.pdf.

Badan Penelitian dan Pengembangan Kesehatan. 2013. Riset Kesehatan Dasar (RISKESDAS) 2013.

Cahyaningsih, D. S. 2011. Pertumbuhan Perkembangan Anak dan Remaja. Jakarta: CV Trans Info Media.

Dinkes Kota Kediri. 2015. Profil Kesehatan Kota Kediri.

Imron, A. 2012. Pendidikan Kesehatan Reproduksi Remaja. Jakarta: Ar-Ruzz Media.

Muhibbin, S. 2000. Psikologi Pendidikan Dengan Pendekatan Baru. Bandung: Remaja Rosdakarya.

Roestiyah, N. 1991. Strategi Belajar Mengajar, Cetakan ke-4. Jakarta: Rineka Cipta.

Romauli, S. 2011. Buku Ajar Kebidanan Konsep Dasar Asuhan Kehamilan. Yogyakarta: Nuha Medika.

Wawan, A. dan Dewi, M. 2012. Teori dan Pengukuran Pengetahuan, Sikap dan Perilaku Manusia. Yogyakarta: Nuha Medika.

Yayasan Kanker Indonesia. 2012. Deteksi Dini Kanker Payudara. Diakses dari: http://yayasankankerindonesia.org/2012. 